\title{
Influence of the diagnosis chronic rhinosinusitis on asthma response to omalizumab in severe, uncontrolled asthmatics
}

\author{
Ina Sintobin ${ }^{1 *}$, Maria del Carmen Vennera ${ }^{2}$, Joaquim Mullol ${ }^{3}$, Claus Bachert ${ }^{4}$ \\ From The 10th Symposium of Experimental Rhinology and Immunology of the Nose (SERIN 2015) \\ Stockholm, Sweden. 19-21 February 2015
}

\section{Background}

Omalizumab is a humanized anti-immunoglobulin E (IgE) monoclonal antibody that has been approved as add-on therapy for the treatment of adults with moderate-tosevere (United States) or severe (Europe) allergic asthma, inadequately controlled after treatment with high-dose inhaled corticosteroids plus long-acting $\beta$-agonists. The clinical efficacy of Omalizumab has not only been shown in the treatment of severe uncontrolled asthma, but also in the treatment of nasal polyposis and comorbid asthma. The aim of this analysis was to examine whether the diagnosis of chronic rhinosinusitis (CRS) influenced the asthma response to Omalizumab treatment.

\section{Methods}

This study retrospectively analysed data from 70 patients with severe, uncontrolled asthma treated with Omalizumab. A skin prick test (SPT) was performed in all patients. In serum, specific Immunoglobulin E (IgE) to Staphylococcal enterotoxins (SE) and total IgE were measured by Immunocap. Asthma response was evaluated by physician's Global Evaluation of Treatment Effectiveness (GETE-score); GETE 0, 1 and 2 were considered as nonresponders, GETE 3 and 4 as responders.

\section{Results}

The mean age of the patients was 54.4 years and $62 \%$ of them were female. $84.3 \%$ of the asthmatics responded to Omalizumab treatment. Within the total patient group, $55.7 \%$ had comorbid nasal polyps and $83.8 \%$ had antibodies to staphylococcal enterotoxins in their serum. Within the SE-IgE positive group, $54.4 \%$ had an excellent GETE score, compared to $30.4 \%$ with good score and $14.3 \%$ with moderate GETE-score. A higher SE-IgE concentration was found in patients with CRS with nasal polyps (CRSwNP) and a strong correlation between SE-IgE and total IgE was observed. The proportion of responders tended to be higher in the group diagnosed with CRSwNP compared to CRS without nasal polyps (CRSsNP), and higher in CRSsNP compared to no CRS ( $89.7 \%$ vs. $85.7 \%$ vs. $81.8 \%$ ); the differences were not statistically significant. The presence of CRS thus did not reduce the overall high response rate to Omalizumab.

\section{Conclusions}

We here showed that a high proportion of severe uncontrolled asthma patients are sensitized to staphylococcal enterotoxins and more than half of these severe asthmatics have comorbid nasal polyposis. There is a trend towards a better asthma response in patients with antibodies to $\mathrm{SE}$ and in patients with CRSwNP.

\section{Authors' details \\ 'Upper Airway Research Laboratory, Ghent University, Ghent, Belgium. ${ }^{2}$ Hospital Clínico de Barcelona, Institut Clínic del Tòrax, Servei de Pneumologia i Allèrgia Respiratòria, Barcelona, Spain. ${ }^{3}$ University of Barcelona, Institut d'Investigacions Biomèdiques August Pi i, Barcelona, Spain. ${ }^{4}$ Ghent University, Upper Airway Research Laboratory, Ghent, Belgium.}

Published: 26 June 2015

doi:10.1186/2045-7022-5-S4-O11

Cite this article as: Sintobin et al:: Influence of the diagnosis chronic rhinosinusitis on asthma response to omalizumab in severe, uncontrolled asthmatics. Clinical and Translational Allergy 2015 5(Suppl 4):O11.

${ }^{1}$ Upper Airway Research Laboratory, Ghent University, Ghent, Belgium

Full list of author information is available at the end of the article 